\title{
Reflections on Fake News, Librarians, and Undergraduate Research
}

\begin{abstract}
Lisa Rose-Wiles
Dr. Lisa Rose-Wiles (Lisa.Rose

-Wiles@shu.edu) is Associate

Professor/Science \& Health Sciences

Librarian at Seton Hall University,

South Orange, New Jersey.

The author would like to thank Tamir Borensztajn, vice-president of Software as a Service Strategy at EBSCO, for inviting her to join a "fake news" panel at the 2017 Charleston Conference and stimulating her interest in this topic. This paper reflects the author's affiliation as a GEM Fellow of the Praxis Program of the Advanced Seminar on Mission, the Center for Vocation and Servant Leadership, and the Center for Catholic Studies, Bernard J. Lonergan Institute at Seton Hall University.
\end{abstract}

Reference \& User Services Quarterly, vol. 57, no. 3, pp. 200-204

๑) 2018 American Library Association. All rights reserved.

Permission granted to reproduce for nonprofit, educational use.
The recent explosion of "fake news" highlights the need for academic libraries to provide access to reliable information resources and for librarians to instruct students in using them effectively. Providing reliable resources with minimal barriers to access involves cooperation among librarians, publishers, and vendors; however, I suggest that there is tension between our mutual desires to satisfy student demands for instant and perfect results and to encourage them to become persistent and critical information seekers. Many tools exist to assist students in gaining background information and limiting search results, but ultimately none replace the need to develop and explore questions and to evaluate information sources. In this paper, I reflect on the difficulties of persuading students to persist in using library resources and the use of Bernard Lonergan's generalized empirical method as a framework for critical thinking and information literacy.

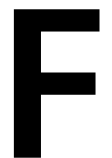

ake news" has become a buzzword since the US election in 2016, but the deliberate creation of false information (disinformation, propaganda) and the misrepresentation or distortion of factual information (misinformation, yellow journalism) are nothing new, especially for librarians. Information in its myriad forms is our daily currency, and providing access to trustworthy information is the primary reason that libraries and librarians exist. But something about the latest manifestation of this phenomenon has caught our attention. A search for "fake news" in almost any database or discovery service will produce a plethora of results, most of them recent publications in the library literature. ${ }^{1}$ Library Quarterly devoted most of its July 2017 issue to the topic, there were at least three sessions at the 2017 Charleston Conference explicitly focused on fake news, and a recent ALA webinar, "Tackling Fake News," drew over eight hundred attendees. ${ }^{2}$ So why the sudden flurry of concern?

One immediate answer is "the Internet and social media" "-indeed, in many databases, the subject associated with fake news is "False news (Social media)." Most millennials-and not only millennials_-spend hours a day on social media, which has become their primary source of information. According to a recent Pew Research Report, two-thirds (67 percent) of Americans get at least some of their news on social media-with two in ten doing so often. ${ }^{3}$ The ease and speed with which items can be received and reposted, "liked," or "retweeted" is phenomenal. A YouTube recording can "go viral" in 
no time. One must wonder how often the information is actually read, let alone understood and evaluated. A related concern is that we live in a "post-truth era," in which information that appeals to the emotions or conforms to personal beliefs is likely to be accepted without question. ${ }^{4}$ As Nicole Cooke eloquently explains, emotional appeal overrides seeking objective or factual answers, facilitating the rapid spread of fake news. ${ }^{5}$ The construction of "filter bubbles" by social media groups and personalized web services means that users can avoid encountering alternate viewpoints and remain in an intellectual enclave that constantly reinforces their preconceptions. ${ }^{6}$

Information that is deliberately faked with malicious or mercenary intent is deeply offensive to librarians and our professional ethics, and it spurs our passion and our mission to promote information literacy. The ability to evaluate information and use it wisely lies at the heart of information literacy. Recently some librarians have adopted the broader term "metaliteracy" to embrace all forms of literacy, including digital media literacy, in the hopes of moving the discussion beyond the perceptual framework of traditional "library instruction"; ${ }^{\prime \prime}$ however, the guiding precept for metaliteracy is still our old friend "critical thinking." Unfortunately critical thinking has also become something of a buzzword and is often ill defined. ${ }^{8}$

One might think that the fake-news phenomenon concerns school and public libraries rather than academic libraries. Academic libraries provide an abundance of vetted information through carefully selected books and journal and database subscriptions as well as research tools and information-literacy instruction. Do these not provide safe information havens for our students and keep them on track to becoming savvy, well-informed researchers? We would like to think so, but as evidenced by the growing number of academic librarians offering fake-news research guides and flocking to fake-news webinars and presentations, we are not immune from the disease. ${ }^{9}$

First, we must remember that our students have lives beyond the academy. They use the Internet and social media on a regular basis for many purposes, and like any member of the public, they need to become informed and critical information users in those domains. Second, not all information needs_even for academic purposes_are for scholarly sources. My experience is primarily in the sciences, where peer-reviewed articles are the gold standard, but assignments in other disciplines often call for news items or other non-peer-reviewed sources. Consider the perennial first-year assignment to "discuss a current controversy." I point those students to databases such as Gale's Opposing Viewpoints or Sage's CQ Researcher to get started, but no doubt many will choose to use Google or a similar search engine. And, of course, many of our databases include newspapers and magazines-typically reputable titles but still not immune to sensational or distorted reporting. Some of the best undergraduate assignments call for a mix of "popular" sources and peer-reviewed articles, with a significant element being to differentiate between and compare them, including evaluating and making a judgment about their authenticity; however, not all instructors require students to use library resources for their assignments, especially in their first year. At our institution, we work closely with teaching faculty who generally do insist students use library databases (of course, whether students actually do so is another question), but this is not always the case. If instructors allow any "reasonable" source, students will inevitably turn to Google for their information needs. Indeed, we often debate whether first-year students should be expected to use scholarly sources and/or whether we should focus on journals and databases that will likely not be available to our students after they graduate. Inevitably such discussions evoke the need to teach students lifelong critical-thinking and information-literacy skills that they can apply to any situation or information source.

I should stress that not all Internet or social media sources are "bad": for example, our computer-science faculty and advanced students inform me that their primary means of scholarly communication are through wikis, blogs, and the like. Citing a first-hand experience, I am embedded in a cross-listed anthropology and women's studies course where we recently had the privilege of a class discussion with feminist writer and poet Naomi Extra. In the course of the discussion, she noted that in addition to a robust body of conventional scholarship, important conversations and debates (especially among black feminist writers and scholars of a particular generation) are also happening on social media and that these sometimes influence the scholarship in pronounced ways. Perhaps our database providers might consider including a selection of these "scholarly blogs" in their indexing, or librarians might consider subscribing to a "scholarly-blog" provider such as the ACI Scholarly Blog Index.

The primary challenge of getting students to use vetted library resources is simply getting them there, as opposed to using a web search engine such as Google. My approach is to supplement the traditional discussion of why Google is not appropriate for scholarly research (no oversight, too many results, too many unreliable results, too many advertisements) with a simple appeal to the pocket. Ironically this is facilitated by the decision by some publishers and vendors (Elsevier among the first) to index their content on Google. This often leads users outside the library environment to encounter a paywall-a demand for payment to access full text. I ask the class if anyone feels they do not pay enough in tuition (a sure laugh maker) and would like to pay again for content they have essentially paid for already. This typically gets the point across.

Assuming we can convince our students to use library resources, multiple challenges remain. One is that many students dive into searching before they have done any background research on their topic and developed a viable research question..$^{10}$ They are in a hurry to get their research done and want to skip that critical step, so their results are all over the place: too many or sometimes too few, seemingly 


\section{FEATURE}

irrelevant or sadly incomprehensible. The resultant frustration leads them to repeatedly change their topic or abandon the library search for their familiar friend, Google. ${ }^{11}$

In addition to librarians repeatedly advising students to "think before they type" and do some background research, there are vendor-supplied tools to help with this problem. Our institution subscribes to EBSCO Discovery Service (EDS), where we encourage undergraduates to begin their research. ${ }^{12}$ The simple EDS search box is front and center of the library home page (we encourage use of the advanced search and individual databases as instruction progresses), and the default keyword search often produces a useful "research starter" as the top result. Results from Credo Reference, usually topic pages, also display on the side of the results screen. Credo Reference is another resource that we vigorously promote for beginning research. We also encourage students to explore Opposing Viewpoints, CQ Researcher, and our recently acquired suite of Gale "In Context" databases to explore topics, gain background, and develop research questions. The latter are particularly promising in their ability to scaffold students from general background to specific articles, and I hope that Gale and other database providers continue to develop and refine similar products.

If the first challenge is getting students to use library resources, the second is surely getting them to persist and develop the habit of doing so. We know that students will quickly abandon a library-based search and revert to Google if they hit a stumbling block. This is particularly true of firstyear students, who usually have limited experience with the structure of library resources and the scholarly literature. One bad experience can deter a student from using a resource-or the entire library-ever again. Not only are illdesigned searches (and library websites) a problem, but the very technology that we rely on to facilitate online research can create unexpected barriers. Any time a link resolver takes me to a journal table of contents instead of the article or produces a 404 error, or clicking "view eBook" links to the wrong title or yields the infamous "handler error" message, I see yet another library user lost to us.

When we are assessing library resources and processes, we should look at platforms and performance from a student perspective. If we want students to persist in using library resources, it is essential that we provide intuitive navigation and seamless linking to full text (or an interlibrary loan request if full text is not available), and minimize barriers such as multiple links, repeated demands for authentication, broken URLs, dead-end looping, or any other sort of message that "you can't get that here." This is particularly applicable to linking between content providers. I appreciate that many of our vendors are competitors for a limited market, but they need to understand that creating barriers between their resources hurts everyone in the long run. We can't run an efficient train service with a bunch of different-sized tracks.

Another challenge to effective use of library resources is that students tend to grab the first few search results that they find. A common scenario is this: "I need three peer-reviewed articles, and I've got them; now I just have to fit them into my paper somewhere." They rarely take time to carefully evaluate their results and persist in their search until they find the best sources for their paper. This is a good example of "satisficing" or "doing what's just good enough to get by," resulting from a combination of unfamiliarity with the peer-reviewed literature, time pressure, and the expectation of instant results that is reinforced by the Internet and social media. ${ }^{13}$ For librarians, I see tension between our desire to satisfy students' demand for instant and perfect results (computer, you read my mind: those three articles are exactly what I need) and to encourage them to dig deeper-to explore, evaluate the results, and persist in their searches as outlined by the ACRL frames "Research as Inquiry" and "Search as Strategic Exploration."14 There is no single or easy answer to this dilemma, but I reiterate the need for careful instruction combined with intuitive website and database design that leads students seamlessly from background research to relevant search results and access to full text without frustrating barriers.

This reflection piece would not be complete without a brief discussion of the trustworthiness of our own library offerings. We put a great deal of faith in our content providers in terms of providing accurate information for us. This is particularly true for the "background" sources to which we direct students beginning their research. I confess I have never sat down and evaluated the content provided by Credo Reference, Gale, and the like for accuracy and inclusiveness. Even if I had the time, I would not be competent to do so for subjects in which I lack extensive knowledge. Indeed, as librarians become increasingly time-pressured multitaskers and the world of information becomes ever more expansive and specialized, we, like our students, tend to abdicate evaluation of content to other "experts" (at least, we sincerely hope they are experts!). This means that our vendors and publishers play a critical role in the process of providing trustworthy information and avoiding not only fake news but also dubious or misleading information in all its forms. Careful curation is particularly important with regard to the recent proliferation of so-called "predatory journals, some of which have been found in various databases. ${ }^{15}$ These journals entice researchers with promises to publish articles quickly_for a price-without the delay of rigorous (or sometimes any) peer review. Most are open-access journals, so by association, this burgeoning business model threatens the legitimate open-access movement that seeks to make research freely available. While not all articles published in predatory journals are "bad," these journals typically have poor editorial practices such as sloppy proofreading and presentation, and a general lack of the professionalism that we expect from peer-reviewed journals. It is probably too much to expect undergraduates to evaluate entire journals, but we should encourage them to evaluate individual articles to the best of their ability.

A useful tool in the struggle to convince our undergraduates to use library resources is the "peer-reviewed" 
box offered by the majority of library databases - a facility notably lacking in Google or Google Scholar. Nonetheless, clicking a box cannot and should not take the place of critical thinking. We must encourage our students to evaluate information as far as their knowledge and experience permits. At our institution, we have had some success in this regard by incorporating Jesuit philosopher Bernard Lonergan's generalized empirical method (GEM) into a variety of courses and library instruction sessions. Lonergan's aim was to explore the common elements of human thinking that could be applied in any discipline. His GEM progression describes a dynamic cognitive process involving experience, understanding, judgment, and action. ${ }^{16}$ The four deceptively simple steps of being attentive to one's experience, intelligent in one's understanding, reasonable in making judgment, and responsible in acting on that judgment align well with the both the scientific method and the new ACRL Framework for Information Literacy. An important component of Lonergan's GEM is our natural desire to ask questions and seek the truth, facilities that often seem repressed in our students and their world of instant answers.

In spring 2013, the Center for Servant Leadership at Seton Hall University initiated the Praxis Advanced Seminar on Mission ("Praxis"), co-sponsored with the Center for Catholic Studies and the Bernard J. Lonergan Institute. ${ }^{17}$ The aim is to connect faculty and administrators in different disciplines to one another and the university mission by studying and applying GEM. The program consists of a semester-long training or immersion in the thought of Bernard Lonergan, with a request for a model of application (Applying the Method, or ATM) to their disciplines at the end. My own ATM involved collaboration with two Praxis colleagues to incorporate GEM into a large first-year biology laboratory course, particularly with regard to information literacy, over a three-year period. ${ }^{18}$ We found that the students' selection, integration, and citation of references improved significantly and that they were writing overall much better lab reports and annotated bibliographies than they had been previously. Another key application of GEM to the first year has been its recent incorporation in the "university life" courses taught by freshman studies mentors to provide integration across disciplines and promote academic and personal success. This has since expanded into the first-year writing program. Since librarians collaborate with freshman studies, the writing center, and first-year English instructors to incorporate information literacy instruction in the curricula, there are multiple opportunities to reinforce GEM during library sessions.

Richard Grallo describes critical thinking as a "vaccine against . . . vagueness, falsehood, runaway wishes, untestable propositions, and incoherent projects."19 We might usefully add "filter bubbles" and "fake news" to this list of "cognitively transmitted diseases," along with the problem of "digital maximization" and "digital distraction," which act against critical reflection and judgment. ${ }^{20}$ While the uncritical acceptance of information is a key problem, the opposite approach of rejecting all information, reputable or otherwise, as lies or falsehoods is perhaps an even more opprobrious response to fake news and the post-truth era. The issue that underlies both responses is the abdication of personal understanding, judgement, and responsibility that should guide informed decision-making. Hopefully a combination of cooperation among librarians, vendors, and publishers in providing carefully curated resources, information-literacy instruction, and training in critical thinking will guide our students-tomorrow's leaders- to become thoughtful information users who easily recognize fake news in its various manifestations.

\section{References}

1. Recent examples include Rick Anderson, "Fake News and Alternative Facts: Five Challenges for Academic Libraries," Insights: The UKSG Journal 30, no. 2 (2017): 6; Marcus Banks, "Fighting Fake News," American Libraries 48, no. 3/4, (2017): 18-21; Bernd W. Becker, "The Librarian's Information War," Behavioral and Social Sciences Librarian 35, no. 4 (2016): 188-91; Linda Frederiksen, "Fake News," Public Services Quarterly 13, no. 2 (2017): 103-7; Peter V. Paul, "Fake News, Alternative Facts, PostTruths, Misinformation, Misinterpretation, and Other Challenges Associated with Knowledge Generation," American Annals of the Deaf 162, no. 1 (spring 2017): 3-7; Nick Rochlin, "Fake News: Belief in Post-truth," Library Hi Tech 35, no. 3 (2017): 386-92.

2. "Post-truth: Fake News and a New Era of Information Literacy," American Library Association (webinar), November 1, 2017, http://www.ala.org/tools/programming/post-truth-fake-news -and-new-era-information-literacy.

3. Elisa Shearer and Jeffrey Gottfried, "News Use across Social Media Platforms, 2017," Pew Research Center, Journalism and Media, September 7, 2017, http://www.journalism.org /2017/09/07/news-use-across-social-media-platforms-2017/.

4. Ralph Keyes, The Post-truth Era: Dishonesty and Deception in Contemporary Life (New York: St. Martin's Press, 2004).

5. Nicole A. Cooke, "Posttruth, Truthiness, and Alternative Facts: Information Behavior and Critical Information Consumption for a New Age," Library Quarterly 87, no. 3 (2017): 211-21.

6. Eli Pariser, The Filter Bubble: How the New Personalized Web Is Changing What We Read and How We Think (London: Penguin Books, 2012); see also Teodora D. Chi, "The Filter Bubble-a Constructivist Approach," Perspectives in Politics / Perspective Politice 9, no. 2 (2016): 5-11.

7. Thomas P. Mackey and Trudi E. Jacobson, "Reframing Information Literacy as a Metaliteracy," College and Research Libraries 72, no. 1 (2011): 62-78.

8. Richard Grallo, "Thinking Carefully about Critical Thinking," Lonergan Review 4, no. 1 (2013): 154-80.

9. For a recent list of fake-news research guides and tools, see Oliver Batchelor, "Getting Out the Truth: The Role of Libraries in the Fight against Fake News," Reference Services Review 45, no. 2 (2017): 143-48.

10. Jennifer A. Dixon, "First Impressions: LJ's First Year Experience Survey," Library Journal, April 13, 2017, http://lj.libraryjournal. com/2017/04/academic-libraries/first-impressions-ljs-first-year -experience-survey/\#_.

11. Beth Bloom and Marta M. Deyrup, "The SHU Research Logs: Student Online Search Behaviors Trans-scripted," Journal of Academic Librarianship 41, no. 5 (2015): 593-601.

12. Lisa M. Rose-Wiles and Melissa A. Hofmann, "Still Desperately Seeking Citations: Undergraduate Research in the Age of WebScale Discovery," Journal of Library Administration 53, no. 2-3 (2013): 147-66. 


\section{FEATURE}

13. Claire Warwick, Jon Rimmer, Ann Blandford, Jeremy Gow, and George Buchanan, "Cognitive Economy and Satisficing in Information Seeking: A Longitudinal Study of Undergraduate Information Behavior," Journal of the American Society for Information Science and Technology 60, no. 12 (December 2009): 2402-15; Lynn S. Connaway, Timothy J. Dickey, and Marie L. Radford, "If It Is Too Inconvenient, I'm Not Going After It': Convenience as a Critical Factor in Information-Seeking Behaviors," Library and Information Science Research 33 (2011): 179-90; Cooke, "Posttruth, Truthiness, and Alternative Facts," 215.

14. Framework for Information Literacy for Higher Education, Association of College and Research Libraries, filed by the ACRL board February 2, 2015, adopted by the ACRL board January 11, 2016, http://www.ala.org/acrl/standards/ilframework.

15. Nerissa Nelson and Jennifer Huffman, "Predatory Journals in Library Databases: How Much Should We Worry?" Serials Librarian 69, no. 2 (2015): 169-92; Marta Somoza-Fernández, Josep-Manuel Rodríguez-Gairín, and Cristóbal Urbano,
"Presence of Alleged Predatory Journals in Bibliographic Databases: Analysis of Beall's List," El profesional de la información 25, no. 5 (2016): 730-37.

16. Bernard J. F. Lonergan, Method in Theology (1971; repr., Toronto: Lonergan Research Institute of Regis College, 1990).

17. "Praxis Program of Advanced Seminar on Mission," Seton Hall University, accessed November 28, 2017, http://www.shu.edu/ vocation-servant-leadership/praxis-program-of-advanced-seminar-on-mission.cfm

18. Lisa M. Rose-Wiles, Marian Glenn, and Doreen Stiskal, "Enhancing Information Literacy Using Bernard Lonergan's Generalized Empirical Method: A Three-Year Case Study in a First-Year Biology Course," Journal of Academic Librarianship 43, no. 6 (2017): 495-508

19. Grallo, "Thinking Carefully about Critical Thinking," 154

20. Conor M. Kelly, "Depth in an Age of Digital Distraction: The Value of a Catholic College in Today's World," Journal of Catholic Higher Education 34, no. 2 (2015): 113-33. 